\title{
Blister Pack
}

National Cancer Institute

\section{Source}

National Cancer Institute. Blister Pack. NCI Thesaurus. Code C43168.

A package that consists of molded plastic or laminate that has indentations (viewed as 'blisters' when flipped) into which a dosage form, is placed. A covering, usually of laminated material, is then sealed to the molded part. A strip pack is a specialized type of blister pack where there are no pre-formed or molded parts; in this case there are two flexible layers that are sealed with the dosage form in between. Suppositories that are strip packed between two layers of foil are also considered a blister pack. 